\title{
Rootpac 40 Anacının Bazı Şeftali ve Badem Çeşitlerine Anaçlık Performansı
}

\author{
Vedat $\operatorname{Er}^{{ }^{*}}$ Hakan Engin ${ }^{1}$ \\ ${ }^{1}$ Çanakkale Onsekiz Mart Üniversitesi Bahçe Bitkileri Bölümü, 17100/Çanakkale \\ *Sorumlu yazar: vedater@seveztarim.com
}

Geliş Tarihi: 12.08 .2018

Kabul Tarihi: 06.12.2018

\section{$\ddot{\mathbf{O} z}$}

$\mathrm{Bu}$ araştırma, Rootpac 40 anacının Çanakkale bölgesinde yoğun olarak yetiştirilen bazı şeftali ve badem çeşitlerine anaç olarak kullanılmasının etkilerinin belirlenmesi amacıyla yapılmıştır. Şeftali ve badem yetiştiriciliğinde bodur ve yarı bodur anaçların kullanılması meyve kalitesi, verim ve gençlik kısırlığı süreleri gibi önemli noktalara etki etmektedir. Son yıllarda bazı meyve türleri için kullanılmaya başlanılan yeni anaçlar üretilmektedir. Söz konusu yeni anaçlardan Rootpac 40, yarı bodur özelliğiyle ön plana çıkmaktadır. Çalışma Çanakkale ili Gelibolu ilçesinde üreticiye ait meyve bahçelerinde yürütülmüştür. Araştırmada Rootpac 40 (Prunus dulcis x Prunus persica) x (Prunus dulcis x Prunus persica) melezi anaç kullanılmıştır. Bu anaç üzerine 6 farklı şeftali çeşidi ve 3 farklı badem çeşidi aşılanmıştır. Aşılama sonucu elde edilen anaç-kalem kombinasyonlarında aşı tutma oranları, taç yükseklikleri ve anaç-kalem kalınlıkları belirlenmiştir. Araştırmamızda elde edilen sonuçlara göre en yüksek aşı tutma oranları, Rootpac 40-Glohaven şeftali (\%98) ve Rootpac 40-Ferragnes badem (\%95) anaç kalem kombinasyonlarında belirlenmiştir. En yüksek taç oluşumu, Rootpac 40-Ferragnes badem, Rootpac 40-Glohaven şeftali anaç kalem kombinasyonlarında belirlenmiştir.

Anahtar Kelimeler: Rootpac 40, yarı bodur anaç, şeftali, badem, yüksek yoğun dikim

\section{The Performance of Rootstock for Rootpac 40 in Some Peach and Almond Cultivars}

\section{Abstract}

This research, Rootpac 40 rootstock was used to determine the effects of using as a rootstock for some peach and almond cultivars grown intensively in the Çanakkale region. The use of dwarf and semi-dwarf rootstocks in peach and almond cultivation affects important points such as fruit quality, yield and the long juvenile period. In recent years new rootstocks have been produced for some fruit species. This is the new rootstock from Rootpac 40 come into prominence of semi dwarfing characteristic. The research was carried out in the orchards belonging to the farmer in the Gallipoli, Çanakkale. (Prunus dulcis x Prunus persica) x (Prunus dulcis x Prunus persica) hybrid Rootpac 40 dwarf rootstock was used in the research. 6 different peach cultivars and 3 different cultivars of almonds were budding this rootstock. The result of budding, rootstock-scion combination, tree size, rootstock-scion vigor was determined. The result of research, the highest budding ratios were determined for Rootpac 40-Glohaven peaches (97\%) and Rootpac 40-Ferragnes almond (94\%) rootstockscion combinations. The highest tree size was determined for Rootpac 40-Ferragnes almond, Rootpac 40Glohaven peach rootstock-scion combinations.

Keywords: Rootpac 40, semi dwarf rootstock, peach, almond, high density system

\section{Giriş}

Meyveciliğin temel unsurlarından olan anaç seçimi tüm dünyada gelişmeleri dikkatle takip edilen önemli konulardan birini teșkil etmektedir. Modern meyve yetiştiriciliğinin ana unsurlarından birisi haline gelen klon anaçları farklı toprak koşullarından (tuzluluk, kireç vs.), hastalık ve zararlılara (nematod, fungal toprak hastalıkları vs.) dayanma, yüksek aşı tutma oranlarından, çoğaltılabilme kolaylıklarına ve bodurlaştırıcı özelliklerine kadar klonal anaçlar öncelikli yetiştiricilik konularından birisi haline gelmiştir (Ilgın, 2004).

Özellikle sık dikime yönelik toprak ve iklim koşullarına uygun anaç geliştirme çalışmaları yoğun bir şekilde yürütülmektedir. Ekonomik açıdan erken ürün verme ve birim alandan maksimum ürün almak için klonal anaç kullanmak gerekmektedir. Klonal anaç kullanımında, genotipin devamlılığı sağlanmakta, üniform populasyon oluşturulabilmekte, gençlik kısırlık dönemini, daha kısa sürmesinden dolayı daha erken dönemde meyveye yatmaktadır. Bu nedenlerden dolayı çeșitli yöre ve toprak koşullarına uygun klonal anaçlar kullanılmalıdır (Arıcı, 2008). 
Aynı meyve çeşidi, değişik anaçlar üzerinde gelişme, meyveye yatma süresi, ürün miktarı ve kalitesi, ağacın ömrü ve ekolojik şartlara adapte olma bakımından önemli farklar göstermektedir (Özçağıran, 1974).

Sert çekirdekli meyve türlerinden olan şeftali ve sert kabuklu meyve türlerinden olan badem dünyada ve ülkemizde sevilerek tüketilen pazar değeri yüksek meyvelerdir. Her ne kadar morfolojik sınıflandırmada şeftali sert çekirdekli meyveler, badem ise sert kabuklu meyveler sınıfına girse de pomolojik olarak şeftali ve badem akrabalık dereceleri yüksek iki meyve türüdür. Bu akrabalık ilişsisi, şeftali ve badem arasında melezleme çalışmalarının yapılmasını ve birbirlerine anaç olarak kullanılmalarını mümkün kılmaktadır (Kaşka ve ark.,1993). Sert çekirdekli ve sert kabuklu meyve türlerinin özel iklim gereksinimleri, kendine özgün fizyolojileri, özel yetiştirme yöntemleri, yetiştirilecek topraklara göre özel fizyolojileri ve yetiştirilecekleri topraklara göre özel anaç istekleri nedeniyle yetiştiricilik yapılacak yerlerde uygun yöntemler uygulanmalıdır. Günümüzde halen devam eden araştırmalarla yeni çeşitler ıslah edilmiş ve böylece badem ve şeftali yetiştiriciliğinin önemli sorunlarını çözümlenmiştir. Yeni ve modern yetiștirme teknikleri uygulayarak birim alandan alınan toplam ürün miktarını artmıştır. Ülkemizin birçok ülkeye göre toprak, iklim, sulama imkanları bakımından üstünlükleri vardır. $\mathrm{Bu}$ nedenle ülkemiz meyve yetiştiriciliğinde modern yöntemler uygulanması zorunluluğu vardır. Anacın meyve özelliklerinin, üzerine aş1lı çeşidin meyvelerine geçmesi söz konusu değildir. Her ne kadar anaçla kalemin meyve özellikleri arasında birbirine karışma yoksa da, anaçlar üzerlerine aşılı çeşidin meyve kalitesine olumlu veya olumsuz şekilde etki yapabilir. Anaç, meyvelerin olgunlaşma zamanı üzerine de etki yapmaktadır (Özçağıran, 1974). Anaçlar, ağaçların gençlik kısırlığı dönemi üzerinde de etki yapmaktadırlar. Ağaçların gençlik kısırlığı süresi, kullanılan anacın gelişme kuvvetine bağlı olarak uzamakta veya kısalmaktadır. Ağaçların yaşama süreleri de üzerinde aşılı bulundukları anaçla yakından ilgilidir (Özçağıran, 1974). Meyve yetiştiriciliğinde birim alandan elde edilecek verimin artırılmasının yollarından biride ağaçları küçülterek birim alana daha fazla sayıda ağaç dikilmesidir. Yarı bodur ve bodur anaçlar, kendi kökleri üzerinde büyüyen ağaçlardan önemli derecede daha küçük ağaç tacı oluşturan anaçlardır. Bol, kısa sürgün oluşturan ağaçlarla, az sayıda fakat uzun sürgün oluşturan ağaçlar karşılaştırıldığında, kütlece benzer olmalarına rağmen uzun sürgün oluşturan ağaçların taç büyüklüğü daha fazladır. Çoğu zaman yoğun dallanan, kütlece büyük olan, ama küçük taç hacimli ağaçlar bodur olarak düşünülebilir (Webster, 1995). Ağaçları küçültme yani bodurluk mekanizmasını etkileyen faktörleri; kök, anaç ve ara anaç, kabuk ve ara anaç, besin elementi alınımı, büyümeyi düzenleyici maddeler, fenoller, taşıma ve çevre şartlarından ileri gelen bodurluklar olarak sıralayabiliriz. Ağaçları küçültmede en etkili yol bodur veya yarı bodur anaç kullanmaktır.

Yeni anaçlardan Rootpac 40, yarı bodur özelliğiyle ön plana çıkmaktadır. Söz konusu araştırmada Rootpac 40 (Prunus dulcis x Prunus persica) x (Prunus dulcis x Prunus persica) melezi anacının farklı şeftali ve badem çeşitlerine anaç olarak kullanım potansiyeli değerlendirilmiştir.

\section{Materyal ve Yöntem}

Çalışma Çanakkale ili Gelibolu ilçesi Yeniköy köyü 24 ve 31 parseller de üreticinin kullanımındaki meyve bahçelerinde yürütülmüştür. Araştırmada Rootpac 40 (Prunus dulcis x Prunus persica) x (Prunus dulcis x Prunus persica) anaçlar kullanılmıştır. Bu anaçlar üzerine Çanakkale bölgesinde yetiştirilen 6 şeftali çeşidi ve 3 badem çeşidi aşılanmıştır. Çalışma Haziran 2015 - Ekim 2017 sezonları arasında yürütülmüsstür. Deneme alanının toprak bünyesi kumlu-tınlı olup, $\mathrm{pH}$ değeri 7,3, toplam N; \%0,03 (çok düşük), alınabilir P; 11,97 ppm (noksan), alınabilir K; 139,79 ppm (orta), organik madde $\% 0,60$ (humusça çok fakir), kireç \%6,47 (orta kireçli), toplam tuz \%0,06 tuzluluk tehlikesi yoktur. Anaç olarak temin edilen Rootpac 40 (Prunus dulcis x Prunus persica) x (Prunus dulcis x Prunus persica) melezi anaçları üzerine Çanakkale bölgesindeki kapama bahçelerden alınan kalemlerden Queen Crest, Glohaven, J.H. Hale, Extreme Red, Royal Gem ve Caldesi 85 şeftalinektarin çeşitleri, Nonperial, Texas ve Ferradual badem çeşitleri aşılanmıştır. Aşılma dilcikli göz aşı yöntemi ile ağustos ayı sonunda 50 yinelemeli olarak yapılmıştır. Aș1lı fidanlar dormant dönemde tüplere alınmış mart ayında sürmeye başlamışlardır. Bu dönemde aşılama verileri kaydedilmiştir. Aşılı tüplü fidanlar ilk baharda deneme parseline $4 \times 1$ (sıra arası x sıra üzeri) metre aralıklarla dikilmiştir. Fidan gelişimine ve anaç kalem gelişimine ait ölçümlere bu dönemde başlanmıştır. Sulama damlama sulama sistemi ile yapılmıştır. Gübreleme fertigasyon yöntemi ile sulama suyu ile birlikte her deneme 
parseline eşit şekilde uygulanmıştır. Morfolojik ölçümler kumpas ve metre ile (taç yüksekliği, anaç kalem kalınlıkları) iki vejetasyon döneminde yapılmıştır. Ağaç taç yüksekliğinde meydana gelen gelişimin saptanabilmesi için, ağacın en yüksek noktasından zemine kadar inen dik esas alınarak, ağacın en yüksek noktasından ilk dal altına kadar olan yükseklik ölçülmüsstür. Her yıl vejetasyon sonunda yapılan ölçümlerle aşı kombinasyonlarına ait yıllık taç yüksekliğinde meydana gelen değişimler saptanmış ve istatistiki olarak değerlendirilmiştir. Anaç kalem kalınlıkları her yıl vejetasyon dönemi sonunda aşı kaynaşma noktasının 1 parmak altından anaç kalınlıkları, aşı kaynaşma noktasının 1 parmak üzerinden kalem kalınlıkları her anaç kalem kombinasyonu için değerler saptanmış ve istatistiki olarak değerlendirilmiştir. Fenolojik gözlemler (pembe tomurcuk, çiçeklenme başlangıcı, tam çiçeklenme, çiçeklenme sonu) iki vejetasyon döneminde yapılmıştır. Pembe Tomurcuk: Tomurcuklarda kabarmanın ilerlemesiyle birlikte, tomurcukların $\% 70^{\circ e}$ inde pembe renkli taç yapraklarının görülmeye başladığı dönemdir. Çiçeklenme başlangıcı: Ağaçtaki çiçeklerin \%5 nin açtığı dönemdir. Tam Çiçeklenme: Ağaçtaki çiçeklerin \%70, \%80'nin açtığı dönemdir. Çiçeklenme Sonu: Taç yaprakların \%95 döküldüğü dönemdir.

Çalışma Şeftali Nektarin ve Badem çeşitlerinde tesadüf blokları deneme desenine göre 3 tekerrürlü olarak planlanmıştır. Çalışma sonunda elde edilen verilerin karşılaştırılmasında SAS ${ }^{\circledR}$ ver.9 istatistik paket programı yardımıyla tek yönlü varyans analizi tekniği kullanılmıştır. Varyans analizi sonucunda önemli olan farklıkların belirlenmesinde ise $\mathrm{p}<0,01$ düzeyinde "Tukey Çoklu Karşılaştırma" testinden yararlanılmıştır. Şeftali Nektarin ve Badem çeşitlerinin bütün anaç kalem kombinasyonlarında, aş1 tutma oranları, taç yüksekliği, anaç-kalem kalınlıkları ölçülmüştür.

\section{Bulgular ve Tartışma}

Queen Crest, Glohaven, J.H. Hale, Extreme Red, Royal Gem ve Caldesi 85 şeftali-nektarin çeşitleri, Nonperial, Texas ve Ferragnes badem çeşitlerinin, Rootpac 40 anacında taç yükseklikleri ve anaç kalem kalınlıkları morfolojik ölçümleri ve aşı tutma oranları Çizelge 1'de sunulmuştur. En yüksek aşı tutma oranı Rootpac 40-Glohaven şeftali, Rootpac 40-Caldesi 85 nektarin ve Rootpac 40Ferragnes badem anaç kalem kombinasyonlarında elde edilmiştir. En düşük aşı tutma oranı ise Rootpac 40-J.H Hale şeftali, Rootpac 40-Extreme Red nektarin ve Rootpac 40-Texas badem çeşitlerinde elde edilmiştir. Aşılma sonrasında 2 yıllık gelişim periyodunda aşı noktalarında herhangi bir anormalliğe rastlanmamıştır.

Çizelge 1. Rootpac 40 Anacı üzerine aş1lı şeftali ve badem çeşitlerinde morfolojik ölçümler (Taç yüksekliği, anaç kalem kalınlıkları) ve aşı tutma oranları (\%).

\begin{tabular}{|c|c|c|c|c|c|c|c|}
\hline \multirow{3}{*}{$\begin{array}{l}\begin{array}{l}\text { Anaç } \\
\text { Rootpac40 }\end{array} \\
\text { Cesit }\end{array}$} & \multirow{2}{*}{\multicolumn{2}{|c|}{$\begin{array}{l}\text { Taç Yüksekliği } \\
\text { (metre) }\end{array}$}} & \multicolumn{4}{|c|}{ Anaç Kalem Kalınlıkları } & \multirow[t]{2}{*}{$\begin{array}{l}\text { Aș1 Tutma } \\
\text { Oranı }(\%)\end{array}$} \\
\hline & & & \multicolumn{2}{|c|}{ Anaç (mm) } & \multicolumn{2}{|c|}{ Kalem(mm) } & \\
\hline & *1.y1l & $* 2 . \mathrm{y} 11$ & *1.y1l & $* 2 . \mathrm{y} 1 \mathrm{l}$ & *1.y1l & $* 2 . y_{11}$ & \\
\hline Nonperial (Badem) & 0,71 & 1,77 & 15,15 & 37,12 & 11,67 & 36,58 & 94,11 \\
\hline Texas (Badem) & 0,74 & 1,77 & 15,45 & 40,04 & 13,08 & 41,62 & 93,88 \\
\hline Ferragnes (Badem) & 0,89 & 1,92 & 17,65 & 37,31 & 15,10 & 39,29 & 94,69 \\
\hline Queen Crest (Șeftali) & 0,58 & 1,64 & 13,21 & 40,74 & 11,62 & 39,24 & 93,38 \\
\hline Royal Gem (Şeftali) & 0,57 & 1,56 & 12,34 & 36,64 & 10,27 & 36,9 & 94,51 \\
\hline ExtremeRed (Nektarin) & 0,60 & 1,57 & 12,50 & 38,35 & 11,52 & 36,05 & 93,28 \\
\hline Glohaven (Șeftali) & 0,63 & 1,74 & 12,82 & 43,09 & 11,55 & 42,42 & 97,6 \\
\hline J.H Hale (Şeftali) & 0,59 & 1,70 & 13,08 & 40,71 & 11,68 & 39,83 & 89,59 \\
\hline Caldesi 85 (Nektarin) & 0,59 & 1,70 & 12,59 & 39,65 & 11,55 & 39,79 & 96,18 \\
\hline
\end{tabular}

*Birinci ve ikinci vejetasyon dönemleri.

Rootpac 40 anacı üzerine aşılı şeftali ve badem çeşitlerinde fenolojik gözlemler yapılmıştır (Çizelge 2). Gözlem sonuçlarına göre șeftali çeşitlerinde en erken Rootpac 40-Queen Crest anaç kalem kombinasyonu, bademlerde Rootpac 40-Nonperial anaç kalem kombinasyonu çiçeklenmekte ve çiçeklenmeyi tamamlamaktadır. En geç çiçeklenmeye başlayıp tamamlayan anaç kalem kombinasyonları ise Rootpac 40-Caldesi 85, Rootpac 40-Ferradual kombinasyonlarıdır. Fenolojik gözlemlerden çögür ve diğer klon anaçlarda erken çiçek açan çeşitler Rootpac 40 anacı üzerinde de 
erken uyanmakta ve çiçeklenmektedirler. Aynı şekilde geç çiçek açan çeşitler Rootpac 40 anacı üzerinde de geç çiçeklenmektedirler.

Çizelge 2. Rootpac 40 Anacı üzerine aşılı şeftali ve badem çeşitlerinde fenolojik gözlemler (Pembe tomurcuk, ilk çiçeklenme, tam çiçeklenme, çiçeklenme sonu) tarihleri.

\begin{tabular}{|c|c|c|c|c|c|c|c|c|}
\hline \multirow{3}{*}{$\begin{array}{l}\begin{array}{l}\text { Anaç } \\
\text { Rootpac } 40\end{array} \\
\text { Çeşit }\end{array}$} & \multicolumn{8}{|c|}{ Fenolojik Gözlemler } \\
\hline & \multicolumn{2}{|c|}{ Pembe tomurcuk } & \multicolumn{2}{|c|}{ İlk Çiçeklenme } & \multicolumn{2}{|c|}{$\begin{array}{l}\text { Tam } \\
\text { Çiçeklenme }\end{array}$} & \multicolumn{2}{|c|}{$\begin{array}{l}\text { Çiçeklenme } \\
\text { Sonu }\end{array}$} \\
\hline & $* 1 . \mathrm{y} 11$ & $* 2 . y 11$ & $* 1 . \mathrm{y} 11$ & $* 2 . \mathrm{y} 11$ & $* 1 . \mathrm{y} 11$ & $* 2 . \mathrm{y} 11$ & $* 1 . \mathrm{y} 11$ & *2.y1l \\
\hline Nonperial (Badem) & $03 / 03$ & $04 / 03$ & $09 / 03$ & $05 / 03$ & $12 / 03$ & $11 / 03$ & $19 / 03$ & $19 / 03$ \\
\hline Texas (Badem) & $03 / 03$ & $05 / 03$ & $10 / 03$ & $07 / 03$ & $14 / 03$ & $12 / 03$ & $20 / 03$ & $20 / 03$ \\
\hline Ferragnes (Badem) & $04 / 03$ & $06 / 03$ & $11 / 03$ & $09 / 03$ & $14 / 03$ & $12 / 03$ & $18 / 03$ & $20 / 03$ \\
\hline Queen Crest (Şeftali) & $11 / 03$ & $12 / 03$ & $20 / 03$ & $18 / 03$ & $25 / 03$ & $22 / 03$ & $30 / 03$ & $29 / 03$ \\
\hline Royal Gem (Şeftali) & $18 / 03$ & $19 / 03$ & $24 / 03$ & $21 / 03$ & $27 / 03$ & $26 / 03$ & $04 / 04$ & $03 / 04$ \\
\hline ExtremeRed(Nektarin) & $17 / 03$ & $19 / 03$ & $23 / 03$ & $19 / 03$ & $26 / 03$ & $24 / 03$ & $03 / 04$ & $31 / 03$ \\
\hline Glohaven (Șeftali) & $16 / 03$ & $18 / 03$ & $22 / 03$ & $18 / 03$ & $25 / 03$ & $23 / 03$ & $31 / 03$ & $31 / 03$ \\
\hline J.H Hale (Şeftali) & $15 / 03$ & $17 / 03$ & $21 / 03$ & $19 / 03$ & $26 / 03$ & $24 / 03$ & $31 / 03$ & $28 / 03$ \\
\hline Caldesi 85 (Nektarin) & $17 / 03$ & $20 / 03$ & $26 / 03$ & $23 / 03$ & $29 / 03$ & $29 / 03$ & $06 / 04$ & $04 / 04$ \\
\hline
\end{tabular}

*Birinci ve ikinci vejetasyon dönemleri.

Rootpac 40 üzerine yapılan bir çalışmada Yahmed ve ark. (2016), Akdeniz ekolojik koşullarında farklı anaç kombinasyonlarını üzerine aşılı badem çeşitlerinin ekolojik ve fizyolojik gelişimlerini araştırdıkları çalışmada anaç olarak Rootpac 40 ve 5 farklı çeșit badem kalemi üzerinde çalışmışlardır. Sonuçta Rootpac 40 anacının Akdeniz koşullarında orta büyüme gücünde en iyi performansı sağladığını saptamışlardır. Çalışmada Rootpac 40 anacının diğer anaçlara göre orta ve hafif bünyeli topraklarda daha iyi geliştiği. Daha kalibreli meyveler oluşturduğu gözlemlenmiştir. Çalışmada diğer bir dikkat çeken husus ise Rootpac 40 anacının saçak kök oluşum teşekkülünün iyi olmasıdır. Jiménez ve ark., (2014)'1 yaptıkları bir çalışmada Rootpac 40 anacına aşılı şeftali çeşitlerinin, yüksek yoğun dikim sisteminde taç büyüklüğü kontrolüne en elverişli anacalar dan birisi olduğunu belirtmişlerdir. Soler ve ark., (2014).'1 Akdeniz koşullarında yaptıkları bir çalışmada, taş çekirdekli meyve yetiştirilen alanlarda yoğun olarak zarar yapan Capnodis (Capnodis tenebrionis L.) zararlısıyla mücadelede kimyasal ve kültürel önlemlerin yeterli olmadığını belirtmiş̧ler, yaptıkları çalışmada sert çekirdekli meyve anaçlarının Caopnodis (Capnodis tenebrionis L.) zararlısına dayanımını araştırmışlardır. Çalışmalarında kullandıkları diğer anaçlarda zararlının kendisini ve köklerde yaptığı hasarı tespit etmişlerdir. Rootpac 40 anacı çalışma sonunda Capnodis (Capnodis tenebrionis L.) zararlısının bulunmadığı ve hasarının görülmediği iki anaçtan biri olduğunu belirtmişlerdir. Yaptığımız çalışmada 2 yıllık deneme sürecinde Rootpac 40 anaçlarında herhangi bir Capnodis (Capnodis tenebrionis L.) zararına rastlanmamıştır. Iglesias ve ark. (2018)'1 İspanya da yaptıkları bir çalışmada Rootpac 40 anacının kullanıldığı şeftali ağaçlarında referans anaç olarak kullandıkları Gf-677, Cadaman ve Garnem anaçlarına göre daha iyi kalibreli meyveler oluştuğunu, daha düşük sürme gücüne sahip olduğunu ve hasat tarihinde uniformluk sağladığını belirtmişlerdir. Çalışmamızın ileriki aşamalarında meyve özellikleri hakkında detaylı bir çalışma yapılacaktır. Gözlemlerde Rootpac 40 anacina aş1lı şeftalilerde meyve kalibrelerinin iyi olduğunu, uniform olgunlaşmanın sağlandığını söylenebilmektedir..

Çizelge 3'de araştırmada kullanılan Rootpac 40 anacı üzerine aşılanan çeşitlerin 2016 ve 2017 yıllarındaki anaç kalem kalınlıkları ve taç yükseklik ölçümlerinin ortalaması istatistiki olarak değerlendirilmiştir. İstatistiki olarak anaç ve kalem kalınlıkları ölçümlerinde önemli düzeyde farklılık bulunmamaktadır. Taç yüksekliği ölçümlerinde önemli düzeyde farklılıklar belirlenmiştir. Çizelge incelendiğinde En yüksek tac1 badem çeşitlerinde Rootpac 40-Ferragnes anaç kalem kombinasyonunda, en düşük tac1 da Rootpac 40-Texas anaç kalem kombinasyonlarında olduğu anlaşılmaktadır. Şeftali çeşitlerinde en yüksek taç Rootpac 40-Glohaven anaç kalem 
kombinasyonunda, en düşük tacın Rootpac 40-Royal gem anaç kalem kombinasyonunda olduğu görülmektedir. En yüksek anaç kalınlığına badem çeşitleri arasında Rootpac 40-Texas badem kombinasyonu, şeftalilerde Rootpac 40-Glohaven anaç kalem kombinasyonu ulaşmıştır. Kalem kalınlıkları incelendiğinde badem çeşitlerinde Rootpac 40-Texas badem, şeftali çeşitlerinde Rootpac 40-Glohaven anaç kalem kombinasyonlarında elde edildiği görülmektedir.

Çizelge 3. Rootpac 40 Anacı 2016 ve 2017 yılı veri değerleri ortalaması.

\begin{tabular}{|l|l|l|c|}
\hline Çeşitler & $\begin{array}{l}\text { Anaç (aşı noktası altı) } \\
\text { Kalınlığı }(\mathrm{mm})\end{array}$ & $\begin{array}{l}\text { Kalem (aşı noktası } \\
\text { üstü) } \\
\text { Kalılı̆̆ğ }(\mathrm{mm})\end{array}$ & Taç yüksekliği $(\mathrm{m})$ \\
\hline Nonperial (Badem) & 26,14 & 24,13 & $1,24 \mathrm{bc}$ \\
\hline Texas (Badem) & 27,75 & 27,35 & $1,26 \mathrm{~b}$ \\
\hline Ferragnes (Badem) & 27,49 & 27,20 & $1,40 \mathrm{a}$ \\
\hline Queen crest (Şeftali) & 26,98 & 25,43 & $1,12 \mathrm{de}$ \\
\hline Royal Gem (Şeftali) & 26,00 & 23,59 & $1,07 \mathrm{e}$ \\
\hline Extreme Red (Nektarin) & 25,43 & 23,79 & $1,09 \mathrm{de}$ \\
\hline Glohaven (Şeftali) & 27,96 & 26,99 & $1,19 \mathrm{bcd}$ \\
\hline J.H Hale (Şeftali) & 26,90 & 25,51 & $1,16 \mathrm{cde}$ \\
\hline Caldesi 85 (Nektarin) & 26,13 & 25,67 & $1,15 \mathrm{cde}$ \\
\hline MSD & Ö.D. & Ö.D. & $\mathbf{0 , 1 0 0 5}$ \\
\hline
\end{tabular}

* Aynı sütunda bulunan farklı küçük harfler istatistiki olarak birbirinden \%1 serbestlik derecesine göre $(p<0,01)$ farklıdır. ** Ö.D.: Önemli değil $(\mathrm{p}>0,01)$

\section{Sonuç ve Öneriler}

Rootpac 40 (Prunus dulcis x Prunus persica) x (Prunus dulcis x Prunus persica) şeftali badem melezi anacı üzerine aşılanan badem ve şeftali çeşitleriyle gerek aşı kaynaşması, gerekse de aşı tutması yönünden iyi sonuçlar vermektedir. Rootpac 40 anacının gelişim periyodunda kalemlerle problem teşkil edecek anormal büyüme ve şekil bozuklukları görülmemiştir. Yapılan araştırmanın ilk bulgularına göre, vejetasyon periyodunda anaç kalem kombinasyonlarının hepsinde çiçek tomurcuğu oluşumu ve çiçeklenmenin sağlıklı bir şekilde tamamlandığı belirlenmiştir. Özellikle badem çeşitlerinde gençlik kısırlığı dönemim kısaltılması açısından ilk yıllarda görülen sağlıklı çiçek tomurcuğu teşekkülü önemlidir. Rootpac 40 anac1 GF-677 anacına göre yaklaşı \% 40 daha az taç oluşturma özelliğine sahip olsa da çok gelişmiş bir saçak kök oluşturduğu gözlemlenmiştir. Çanakkale bölgesinde Rootpac 40 anacı üzerine aşılı şeftali ve badem bahçesi tesis etmek, yüksek yoğun dikimle iyi bakım koşullarında yüksek verim ve kaliteli meyve elde edilebilir. Özellikle şeftali de erkenci ve geçci çeşitler aşılanarak tesis edilecek bahçelerde ortalamanın üstünde kaliteli meyve alınarak, 1skarta meyve oranı azaltılabilir. Bu durum, ekonomik geliri yüksek oranda arttırılabilir. Anaç hakkında daha iyi araştırma yapılarak bölgede kullanılan mevcut ve anaçlara olan üstünlükleri zayıflıkları araştırılmalıdır. Dikim sıklığı, erken meyveye yatma özelliği, kaliteli meyve oluşturması anacı cazip hale getirmektedir.

Not: Bu makale ÇOMÜ Fen Bilimleri Enstitüsü Bahçe Bitkileri Anabilim Dalı Öğrencisi Vedat Er'in" Rootpac 20 ve Rootpac 40 Anaçlarının Bazı Şeftali ve Badem Çeşitlerine Anaçlık Performansları" isimli Yüksek Lisans tez çalışmasından türetilmiş̧ir.

\section{Kaynaklar}

Arıcı, Ş., E., 2008. Bazı Sert Çekirdekli Meyve Anaçlarının Doku Kültürü İle Çoğaltılması. Süleyman Demirel Üniversitesi, Ziraat Fakültesi, Bitki Koruma Bölümü, 32260, Çünür, ISPARTA

Eroğlu, Z., Ö., Mısırlı, A., 2012 Şeftali Gelişimi ve Islahı, Atatürk Üniversitesi Ziraat Fakültesi Bahçe Bitkileri Bölümü, Erzurum.

Iglesias, I., Carbó, J., Bonany, J., Garanto, X., Peris, M., 2018, Revista de fruticultura, ISSN 2013-5742, N. 61, pages 6-42. Spain.

Jiménez, S., Pinochet, J., and Romero, J., 2004. Performance of peach and plum based rootstocks of different vigour on a late peach cultivar in replant and calcareous conditions. Scienta. Hort. 03.006.

Kaşka, N., Ak, BE., Nikpeyma, Y., 1992. Antepfistığı yetiştiriciliğinde saçak köklü çöğür ve fidan yetiştirme üzerine bir araştırma. I.Ulusal Bahçe Bit. Kongresi Bildiriler Kitabı, s:89-92. İzmir. 
ÇOMÜ Zir. Fak. Derg. (COMU J. Agric. Fac.)

2018: 6 (Özel Say1): 71-76

ISSN: 2147-8384 / e-ISSN: 2564-6826

Ilgın, M., Bulat, L., 2014. GF-677 Klon Anacında Çelik Alma Zamanı İle Farklı Dozlardaki IBA (Indol-3 bütirik asit) Uygulamalarının Köklenme Başarısına Etkileri. K.S.Ü. Ziraat Fakültesi Bahçe Bitkileri Bölümü, Avşar Yerleşkesi, Kahramanmaraş.

Özçağıran, R., 1974. Meyve ağaçlarında anaç ile kalem arasındaki fizyolojik ilişkiler. Ege Üniv. Zir. Fak. Yay. No:243, İzmir, s.6-14.

Soler, A., Torrents, J., Dicenta, F., 2014. RESISTANCE TO CAPNODIS TENEBRIONIS IN NEW PRUNUS ROOTSTOCKS. Acta Hortic. 1028, 201-204.

Webster, A.D., 1995. Rootstock and interstock effects on deciduous fruit tree vigour, precocity, and yield productivity. New Zealand Journal of Crop and Horticultural Science, Vol. 23: 373-382.

Yahmed, J., Mohamed G., Mehdi, M., 2016. Eco-physiological evaluation of different scion-rootstock combinations of almond grown in Mediterranean conditions, Institut National Agronomique de Tunisie, 43 avenue Charles Nicolle, 1082, Tunis, Tunisie. 